\title{
Mulheres em cargos profissionais de chefia: \\ o paradoxo da igualdade
}

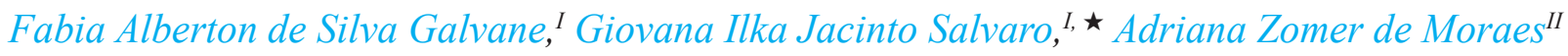 \\ ${ }^{I}$ Universidade do Extremo Sul Catarinense, Criciúma, SC, Brasil \\ II Centro Universitário Barriga Verde, Orleans, SC, Brasil
}

\begin{abstract}
Resumo
O artigo aqui apresentado foi construido a partir de informações obtidas em uma pesquisa realizada no ano de 2009, apresentada como Trabalho de Conclusão de Curso da Psicologia, ao Centro Universitário Barriga Verde - UNIBAVE (GALVANE, 2009). A pesquisa teve como objetivo geral verificar os sentidos produzidos por mulheres que ocupam cargos de chefia em indústrias de uma cidade do sul de Santa Catarina, Brasil. O modelo de pesquisa foi o qualitativo proposto por González Rey (2005). Os sujeitos da pesquisa foram sete mulheres e as informações obtidas por meio de entrevistas semiestruturadas. Neste artigo, propõe-se revisar informações obtidas e ampliar discussões outrora realizadas, utilizando-se das contribuições teóricas de Joan Scott e Judith Butler. Entre outras questões relevantes, o estudo sugere que as entrevistadas utilizam concepções baseadas em "certa essência feminina" como estratégia de visibilidade, permanência e poder no mercado de trabalho.
\end{abstract}

Palavras-chave: igualdade de gênero; desigualdade de gênero; trabalho; estratégias de poder.

\section{Women in leadership: the equality paradox}

\begin{abstract}
The article presented here was constructed from information obtained in a research held in 2009, presented as a Psychology Monograph at the Centro Universitário Barriga Verde - UNIBAVE (GALVANE, 2009). This study aimed to determine the meanings produced by women who occupy leadership positions in industries of a southern town of Santa Catarina, Brazil, and followed the qualitative research model proposed by González Rey (2005). The respondents were seven women and information obtained through semi-structured interviews. This article, however, proposes to revise and expand information obtained from discussions held previously using, among others, the theoretical contributions of Joan Scott and Judith Butler, by which they questioned gender differences based on binary and naturalized conceptions. Among other relevant issues, the study suggests that the respondents use concepts based on "a certain feminine essence" as a strategy of visibility, presence and power in the labor market.
\end{abstract}

Keywords: gender equality; gender inequality; work; power strategy.

\section{Introdução}

$\mathrm{O}$ artigo aqui apresentado foi construído a partir de informações obtidas em uma pesquisa realizada no ano de 2009, originalmente apresentada como Trabalho de Conclusão de Curso da Psicologia, ao Centro Universitário Barriga Verde- UNIBAVE. Na ocasião, a referida pesquisa teve como objetivo geral verificar os sentidos produzidos por mulheres que ocupam cargos de chefia em indústrias de uma cidade do sul de Santa Catarina, Brasil, e seguiu o modelo de pesquisa qualitativa proposto por González Rey (2005), que pressupõe a construção de indicadores e zonas de sentido no processo de análise. Por se debruçar sobre temas como gênero e trabalho, sua construção exigiu o diálogo com as áreas de conhecimento da economia, psicologia, filosofia, história, sociologia. Os sujeitos entrevistados foram sete mulheres, com idades entre 28 e 53 anos, que ocupavam cargos de chefia em indústrias localizadas em um município do sul de Santa Catarina. A chefia foi caracterizada pelo registro em carteira de trabalho em cargos que possibilitam certa autonomia e liderança, gerência ou chefia de outros trabalhadores ou de processos. Os cargos ocupados pelas entrevistadas no momento da entrevista eram: gerente de setor de peças de reposição, gerente administrativa, gerente do setor de expedição, líder de turno de empaco-

\footnotetext{
^Endereço para correspondência: Universidade do Extremo Sul Catarinense. Av. Universitária, 1105 - Universitário. CEP: 88806-000. Criciúma, SC - Brasil.E-mail: biagalvani@hotmail.com, giovanailka@gmail.com, azomermoraes@gmail.com
}

tamento, gerente de recursos humanos, chefe de faturamento e chefe do setor financeiro. Quanto à escolaridade, quatro mulheres concluíram o ensino médio completo, duas são graduadas na área em que trabalham, uma é graduada em uma área distinta da que trabalha e é pós-graduada na área em que trabalha. A aproximação foi realizada por acessibilidade e as informações obtidas por meio de entrevistas semiestruturadas.

No presente artigo, propõe-se a revisão e ampliação de algumas discussões outrora realizadas. Em grande medida, as informações obtidas ao longo da pesquisa evidenciaram que, mesmo participando efetivamente de espaços até então considerados como "lugares de homens", os conteúdos dos relatos das mulheres entrevistadas remontam a crença em uma "essência feminina" que, segundo as mesmas, é fundamental para diferenciá-las e qualificá-las profissionalmente em relação aos homens. O que se pretende apresentar é uma análise de tais informações a partir de contribuições teóricas, entre outras, de Judith Butler e Joan Scott. Os trabalhos destas duas autoras "têm posto em questão a diferença entre sexo e gênero, enfatizando ainda mais o afastamento em relação ao essencialismo" (PEDRO, 2005, p. 90). Estudos feministas têm buscado formas de romper com a noção de uma diferença entre homens e mulheres baseada na anatomia. Entretanto, conforme Mara Lago (1999) ultrapassar os limites naturalizantes que marcam concepções acerca das mulheres foi (e ainda é) um grande desafio. 
As principais discussões a respeito das desigualdades entre homens e mulheres são marcadas por concepções apoiadas em características biológicas, principalmente, aquelas relacionadas com a reprodução. Simone de Beauvoir (1968, p. 25), na obra $O$ segundo sexo, referência importante nos estudos sobre mulher e relações de gênero, descreve que a mulher, de forma bem simplificada, é compreendida como a fêmea do homem, e que o termo "fêmea" tem uma conotação "[...] pejorativa, não porque enraíze a mulher na Natureza, mas sim porque a confirma em seu sexo". Ao buscar elementos que justifiquem a subordinação da mulher em relação ao homem, Beauvoir (1968) encontra concepções que descrevem a mulher como sujeito determinado pelo sexo.

Há uma tendência em explicar o comportamento, as atividades e as relações sociais das mulheres como naturais, determinadas desde o nascimento e, portanto, imutáveis. Esta forma arbitrária de se utilizar a natureza contribui para que as mulheres sejam relacionadas à esfera privada e os homens à esfera pública. Em seu livro, Mística Feminina, publicado em 1971 e também considerado uma obra fundamental para as discussões sobre a condição de mulheres na sociedade ocidental, principalmente da mulher americana, Betty Friedan descreve que na metade do século XX, período pós-guerra, houve extrema valorização do papel de dona de casa assumido pela mulher americana. Beauvoir e Friedan são consideradas autoras fundamentais para os movimentos feminista do período pós-guerra.

Pedro (2005), fundamentada em Delphy (2000), ressalta que os movimentos feministas têm apresentado certas "ondas". Para a autora, o feminismo de "primeira onda" foi marcado pela reivindicação de direitos políticos e econômicos e, o feminismo de "segunda onda", chamado também de "feminismo da diferença", buscou uma identidade feminina, baseada no direito ao corpo e na luta contra subordinação das mulheres em relação aos homens. Simone de Beauvoir e Betty Friedan são autoras que representam os movimentos feministas de "segunda onda" e, "foi justamente na chamada "segunda onda' que a categoria 'gênero' foi criada, como tributária das lutas do feminismo e do movimento de mulheres" (PEDRO, 2005, p. 79).

As feministas, igualitaristas ou diferencialistas, tinham o objetivo comum de compreender como, nas mais diversificadas culturas, as mulheres eram submetidas à autoridade masculina. "Assim, constatavam, não importava o que a cultura definia como sendo atividade de mulheres: esta atividade era sempre desqualificada em relação àquilo que os homens, desta mesma cultura, faziam" (PEDRO, 2005, p. 83).

Estudos feministas sugerem que concepções estereotipadas acerca das habilidades das mulheres, considerando-as naturalmente aptas a determinadas atividades, tais como o cuidado com a casa e com os filhos, podem reforçar a desvalorização das mulheres no mercado de trabalho e sustentar barreiras invisíveis que dificultam o acesso das mesmas a cargos de mais prestígio e com maior remuneração dentro das organizações (ABRA-
MO, 2007; CAPPELLIN, 2008). Entretanto, os discursos das mulheres entrevistadas remontam a crença em uma essência feminina, que, segundo as mesmas, é fundamental para diferenciá-las e qualificá-las profissionalmente em relação aos homens, o que contribui para evidenciar relações de poder.

Tendo em vista tais considerações introdutórias, cabe apresentar os principais pressupostos teóricos que orientam a reflexão aqui proposta.

\section{Alguns apontamentos teóricos}

\section{Feminismo e gênero como categoria de análise}

A diferenciação entre uma fêmea e uma mulher exigiu que se pensasse em uma categoria de análise que possibilitasse compreender a mulher como sujeito produzido nas/pelas relações sociais e culturais. De acordo com a historiadora norte-americana, Joan Scott (1995, p. 85), no clássico artigo Gênero: uma categoria útil de análise histórica, "as preocupações teóricas relativas ao gênero como categoria de análise só emergiram no fim do século XX." Na definição proposta pela autora, “(1) o gênero é um elemento construtivo de relações sociais baseadas nas diferenças percebíveis entre os sexos e (2) o gênero é um primeiro modo de dar significado às relações de poder". (SCOTT, 1995, p. 86). A autora descreve, ainda, que feministas americanas passaram a utilizar o termo gênero na tentativa de romper com modelos que determinam a mulher a partir de seu sexo e, principalmente, insistir no caráter social das diferenças e subordinações entre os sexos. Muitas teorias construídas a respeito das diferenças entre homens e mulheres tinham sua base na biologia, fato que dificultou que o termo gênero possibilitasse novas direções de análise.

$\mathrm{O}$ termo gênero faz parte da tentativa empreendida pelas feministas contemporâneas para reivindicar um certo terreno de definição, para sublinhar a incapacidade das teorias existentes para explicar as persistentes desigualdades persistentes entre as mulheres e os homens (SCOTT, 1995, p. 85).

O uso do gênero como categoria de análise permite o estranhamento de modelos sociais concebidos a priori. Em alguns estudos o termo gênero foi utilizado como sinônimo de mulher. No entanto, segundo Scott (1995), os estudos acerca das relações de gênero não se referem exclusivamente à mulher, sendo que uma mulher somente se apresenta como desigual em relação a outro, neste caso, em relação ao homem. Compreender o gênero como uma importante categoria de análise é possibilitar um olhar diferente no que diz respeito às relações sociais e, portanto, às relações de sujeição da mulher em relação aos homens no decorrer da história. "O gênero, então, fornece um meio de decodificar o significado e de compreender as complexas conexões entre várias formas de interação humana" (SCOTT, 1995, p. 89). Neste sentido, o gênero como uma categoria de análise possibilita ampliar o leque de discussões a respeito das relações estabelecidas entre homens e mulheres, mulheres e mulheres, homens e homens.

Fractal, Rev. Psicol., v. 27 - n. 3, p. 301-309, 2015 
O grande desafio dos estudos de gênero é superar concepções de uma realidade imutável e, de certo modo, compreender como os discursos normativos acerca das relações de gênero se concretizam no cenário político, privado, econômico e histórico dos quais os sujeitos participam. Segundo explica Pedro (2005), para Scott (1995), a categoria gênero é apresentada como um saber que produz significados a respeito das diferenças percebidas entre os sexos. Para outros/as autores/as, dentre eles/ as a filósofa estadunidense Judith Butler, o próprio sexo é um resultado "discursivo/cultural", pois as diferenças sexuais não são anteriores à cultura. Para Butler (2010), considerar o gênero como uma forma de dar sentido aos corpos tem um efeito tão determinante quanto o da biologia, sendo que, as explicações, mesmo sendo culturais, repousam nas diferenças anatômicas.

Quando a "cultura" relevante que "constrói” o gênero é compreendida nos termos dessa lei ou conjunto de leis, tem-se a impressão de que o gênero é tão determinado e tão fixo quanto na formulação de que a biologia é o destino. Nesse caso, não a biologia, mas sim a cultura se torna o destino. (BUTLER, 2010, p. 26).

Butler (2012) afirma que são os discursos normativos de gênero que produzem os corpos. São esses mesmo discursos que possibilitam que certos tipos de sexualidade sejam vividos ou não. Dito de outra forma, o poder de um discurso normativo de gênero não se limita a regular as relações entre homens e mulheres e uma sociedade ou cultura, mas, em instituir o que é ser homem ou ser mulher. Em seu livro Deshacer el gênero, Butler (2012) descreve que as práticas sociais são apoiadas por normas - implícitas ou explícitas - que operam na normalização dos indivíduos. Ainda, para a autora, são as normas implícitas aquelas difíceis de serem percebidas e, frequentemente, as mais poderosas na regulação do princípio normalizador.

Utilizando-se dos estudos de Foucault, Butler faz um alerta para o poder das normas de gênero na produção daqueles/as que normalizam. Para Butler (2012, p. 70), "el género es el aparato a través del cual tiene lugar la producción de lo masculino y lo femenino junto con las formas interstiales hormonales, cromosómicas, psíquicas y performativas que el género asume". ${ }^{1}$ Segundo a autora, o gênero poderia (deveria) ser utilizado para desconstruir e desnaturalizar as noções de feminino e masculino, questionando a regulação de um poder que, ao naturalizar as relações entre homens e mulheres, reduz as possibilidades de alterações nestas relações.

Em seu livro Problemas de gênero - feminismo e subversão da identidade, Butler (2010, p. 20) descreve que "a invocação performativa de um 'antes' não histórico torna-se a premissa básica a garantir uma ontologia pré-social de pessoas que consentem livremente em ser governadas, constituindo assim a legitimidade do contrato social". Dito de outra forma, acreditar que a noção binária de masculino e feminino é dada a priori, desvinculada dos processos históricos e dos discursos jurídicos e políticos

\footnotetext{
'O gênero é o aparato através do qual tem lugar a produção do masculino e do feminino junto com as formas inter-relacionadas hormonais, cromossômicas, psíquicas e performativas que o gênero assume (Tradução livre).
}

que regem determinada cultura, é acreditar que os corpos são naturalmente determinados. É dizer que existe uma essência masculina e feminina e, portanto, aquilo que foge ao padrão esperado (regulado) de comportamento é tido como anormal, pois não oferece inteligibilidade.

A categoria gênero deveria possibilitar a desconstrução de um sujeito estável do feminismo por meio do qual se busca representar todas as mulheres. Ao evocar esse sujeito como forma de reivindicar espaços e lutar contra desigualdades sociais e culturais, os movimentos feministas correm o risco de reificar os discursos normativos que regem as relações de gênero, fato que, vai contra os objetivos do próprio feminismo (BUTLER, 2010). Em seu artigo $O$ enigma da igualdade, Scott (2005) descreve que, muitas vezes, os indivíduos lançam mão de certa "essencialidade" com o intuito de serem vistos e ouvidos no contexto político em que vivem.

O elevado senso de identificação que surge com a redução de um indivíduo a uma categoria é, ao mesmo tempo, devastador e embriagador. Como objeto de discriminação, alguém é transformado em um estereótipo; como membro de um movimento de luta, esse alguém encontra apoio e solidariedade (SCOTT, 2005, p. 19).

Como forma de participar de um grupo com força suficiente para reivindicar espaços, os indivíduos abraçam os estereótipos da categoria a que pertencem. $\mathrm{Na}$ tentativa de escapar da subordinação causada pela crença de uma essência feminina que associa mulheres a maternidade e a realização das atividades domésticas, os movimentos feministas correm o risco de reificarem o discurso de uma identidade feminina una, reproduzindo, desta forma, as mesmas normas das quais tentam escapar.

Com base no que ressaltam Scott e Butler acerca dos feminismos e da categoria gênero, é possível considerar que a interface gênero e trabalho, temática em torno da qual a reflexão deste artigo é mobilizada, requer considerações e problematizações.

\section{Gênero e trabalho}

Ao olhar atentamente o mercado de trabalho, pode-se perceber que apesar da inserção incontestável das mulheres neste espaço, trata-se de participações prevalecentes em determinadas áreas e, ainda, desvalorizadas em relação aos homens. Existem atividades consideradas historicamente femininas e masculinas, com características definidas e atribuídas, na maioria das vezes, a partir de habilidades consideradas inatas, uma visão de que homens nasceram para tais funções e mulheres nasceram para outras. A naturalização da divisão sexual do trabalho dificultou produções que questionassem as concepções acerca da força de trabalho feminina.

No que diz respeito ao campo de estudos sobre mulheres e trabalho, é central considerar o pioneirismo dos estudos de Heleieth Saffioti, intitulado "A mulher na sociedade de classes: mito e realidade" 2 e de Elisabeth

${ }^{2}$ Essa obra de Heleirth Saffioti foi publicada como livro pela primeira vez em 1969. A obra utilizada aqui é uma versão publicada em 2013, como homenagem ao trabalho pioneiro da autora. 
Souza-Lobo (1991), "A classe operária tem dois sexos: trabalho, dominação e resistência". Entre outras questões, Souza-Lobo trata da interface relações de gênero e divisão sexual do trabalho, de modo a evidenciar que atividades femininas são marcadas pela hierarquia de gênero, apresentam desigualdades salariais e desqualificação.

Ao tratar de alguns estudos sobre trabalho feminino, Souza-Lobo (2011, p. 199) destaca que, embora alguns buscassem o rompimento com modelos biológicos, acabavam por privilegiar uma visão estrutural da divisão do trabalho e/ou tendiam "[...] a privilegiar a organização familiar e seu projeto estratégico, subsumindo integralmente as mulheres como atores sociais". A partir da década de 1980, alguns estudos a respeito da organização do trabalho fabril abrem espaço para a problemática do trabalho feminino. De acordo com a autora, alguns estudos permitiram perceber que na divisão sexual do trabalho existem setores de empregos distintos entre homens e mulheres que são articulados por "qualificações" consideradas masculinas e femininas. Assim, o trabalho feminino não se apresentava como uma força de trabalho reserva como alguns estudos insistiam, entretanto, era marcado por concepções naturalistas que empregavam as mulheres de acordo com "os talentos femininos".

Souza-Lobo (2011, p. 203) observa que "a noção de gênero remete ao discurso sobre o masculino e feminino naquilo que parecia exclusivamente uma relação técnica-organizativa" e, assim sendo, o uso do conceito "na sociologia do trabalho coincide com a problematização das subjetividades e também com as identidades presentes no mundo do trabalho". O gênero como categoria de análise no trabalho permite não somente questionar o discurso sobre "os denominados trabalhos masculinos e femininos", mas também possibilita compreender as relações de poder entre os sexos no contexto do trabalho.

Segundo Foucault (1995, p. 240), o poder "coloca em jogo relações entre indivíduos (ou entre grupo)", ou seja, o termo “designa relações entre 'parceiros' (entendendo-se por isto não um sistema de jogo, mas apenas - e permanecendo, por enquanto, na maior generalidade - um conjunto de ações que se induzem e se respondem umas às outras)".

No caso desta pesquisa, é possível considerar que a mesma "essência feminina" como afirma Melo (2009), que pode ser considerada a gênese do papel social subalterno feminino, é usada como estratégia de poder, de diferenciação e de qualificação das mulheres em relação aos homens. A diferença é utilizada como uma ferramenta importante na busca da igualdade. A "essência feminina", a mesma rejeitada pelos movimentos feministas, pode ser invocada como forma de conquistar espaços na esfera pública.

A partir do que discute Foucault acerca do poder, Butler (2012, p. 68) refere-se à sujeição e regulação dos indivíduos.

1) El poder regulador no sólo actua sobre un sujeto preexistente, sino que también labra y forma

${ }^{3}$ Vinte anos após a morte de Elisabeth Souza-Lobo, no ano de 2011, a Editora
Fundação Perseu Abramo publicou a $2^{\mathrm{a}}$ edição do livro "A classe operária tem dois sexos: trabalho, dominação e resistência". al sujeto; además, cada forma jurídica de poder tiene su efecto productivo; y 2) estar sujeto a un reglamento es también estar subjetivado por el; es decir, devenir como sujeto precisamente a través de la reglamentación. Este segundo punto se desprende del primero en la medida en que los discursos reguladores que forman al sujeto del género son precisamente aquellos que requieren e inducen al sujeto en cuestión ${ }^{4}$.

Uma norma reguladora, desta forma, não somente regula as relações entre os sujeitos, mas também produz os sujeitos que regula. Foucault $(1979$, p. 150) afirma que a coerência de uma norma não deriva de um projeto, "[...], mas da lógica de estratégias que se opõem umas as outras". Segundo o autor, é pelo estudo dos mecanismos que penetram nos corpos, nos gestos, nos comportamentos, que é preciso construir a arqueologia das ciências humanas. Os estudos acerca de relações de poder, para Foucault (1979), devem vislumbrar o questionamento, a percepção a longa distância de pontos sutis que disciplinam e normalizam as relações entre os sujeitos.

Neste sentido, a participação de mulheres no mercado de trabalho pode ser analisada a partir do "paradoxo da diferença e igualdade". Scott (2005) explica que, embora existam diferentes definições para o termo paradoxo, geralmente ele está relacionado a posições contrárias em um mesmo contexto, ou a uma ideia que vai contra uma verdade pré-estabelecida. Um paradoxo é formado por polos contrários e, nem sempre é possível se posicionar a favor de um deles. No caso da reificação de certa essência feminina, existente em concepções acerca de atividades realizadas por mulheres no mercado de trabalho, vê-se seu uso como forma de discriminação e desvalorização da mão de obra feminina, mas também como forma de inclusão social pela diferença.

Ao lançarem mão de certa essencialidade feminina, como forma de inclusão em espaços considerados masculinos, as mulheres reificam normas reguladoras de gênero. Para Butler (2012), uma norma somente persiste como reguladora nas $\backslash$ pelas práticas sociais. Por meio de rituais diários, na maioria das vezes difíceis de serem observados, uma norma é reproduzida e incorporada como discurso normalizador.

\section{Análise e discussão dos resultados}

Nesta pesquisa, os "dados" obtidos pelas entrevistas não foram transformados em categorias de análise rígidas, mas sobre eles foi lançado um olhar atento que possibilitou a elaboração de "indicadores". González Rey, (2005, p. 118) descreve que "o desenvolvimento dos indicadores conduz necessariamente ao desenvolvimento de conceitos e categorias novas no curso de uma pesquisa, o que é, talvez, um dos momentos mais criativos e delicados da pesquisa". A utilização de indicadores na

${ }^{4}$ 1) O poder regulador não somente atua sobre um sujeito pré-existente, mas também lavra e forma ao sujeito; além do mais, cada forma jurídica do poder tem seu efeito produtivo; e 2) estar sujeito a um regulamento é também estar subjetivado por ele; ou seja, vir a ser como sujeito precisamente através da regulamentação. Este segundo ponto se desprende do primeiro na medida em que os discursos reguladores que formam ao sujeito do gênero são precisamente aqueles que requerem e induzem ao sujeito em questão. (Tradução livre).

Fractal, Rev. Psicol., v. 27 - n. 3, p. 301-309, 2015 
pesquisa qualitativa visou romper com modelos que utilizam o momento empírico meramente como coleta dados. Em tal proposta, a análise de conteúdo pode ser orientada "para a produção de indicadores sobre o material analisado que transcendam a codificação e o convertam em um processo construtivo e interpretativo" (GONZÁLEZ REY, 2005, p. 146). Assim sendo, a análise de conteúdo como processo construtivo e interpretativo possibilitou a elaboração das categorias de análise que seguem.

\section{Trajetórias profissionais de mulheres em cargos de chefia e normas de gênero}

A análise das trajetórias profissionais das entrevistadas possibilita compreender os caminhos que foram percorridos até a ocupação dos atuais cargos. Pode-se verificar que estas trajetórias foram (são) marcadas por atividades historicamente consideradas femininas.

Aos nove anos eu era babá, depois fui doméstica. Aos 17 fui trabalhar em uma indústria de plástico meio periodo e no outro continuei como doméstica para ter uma renda maior. [...] hoje aqui eu faço de tudo, eu vendo, atendo telefone, varro, organizo (Luciana). ${ }^{5}$

Eu comecei aos treze anos. Eu limpava, arquivava e organizava tudo [...]. Trabalhei em um órgão de saúde pública, depois em um centro comunitário [...] trabalhei junto à secretaria municipal de saúde, no fórum [...] sempre vinculada a serviços sociais (Neide).

Assim que casei trabalhei um tempo na roça e fazia almoço para os outros [...] tentei ser professora, mas não deu certo [...] quando comecei aqui, eu era tudo, limpava o galpão, ia ao banco, fazia o café (Aparecida).

Comecei na agricultura com treze anos [...] aí, com dezessete anos fui empacotadora em outra indústria, e depois nesta. Aqui eu sou muito organizada, eu que limpo, que guardo as coisas, varro [...] atendo pessoas [...] tem que ter bastante disciplina para dar conta (Lucia).

Embora estas trajetórias profissionais sejam singulares, envolvendo diferentes atividades e cargos, é possível observar a constante "marca do feminino" das atividades realizadas no contexto doméstico. Friedan (1971) descreveu que durante muitos anos, principalmente, no período pós-guerra, as mulheres eram treinadas exclusivamente para cuidarem dos serviços domésticos. A imagem da dona de casa americana feliz e realizada com o trabalho doméstico era tão forte que, segundo a autora, não se sentir feliz em realizar tais atividades gerava um "problema sem nome". As falas das entrevistadas demonstram que, após consideráveis avanços na vida profissional, de certa forma, as mulheres reificam algumas normas de gênero.

Scott (2005, p. 15) descreve que, mesmo depois da promessa por igualdade realizada na época da Revolução Francesa, as mulheres tiveram sua cidadania negada, pois "[...] seus deveres domésticos e de cuidados com as crianças eram vistos como impedimentos à participação política”.

\footnotetext{
${ }^{5}$ Os nomes das entrevistadas utilizados na análise são fictícios.
}

Como se pode perceber nas entrevistas, é justamente pela confirmação de certa essência feminina, utilizada outrora como discurso normativo que negava às mulheres a participação no mundo político, que estas se inserem no mercado de trabalho. Neste sentido, é possível destacar aqui o paradoxo que envolve as trajetórias profissionais destas mulheres. Segundo Scott (2005, p. 14), um paradoxo desafia uma verdade ortodoxa, é algo que não pode ser resolvido de forma definitiva, pois é verdadeiro e falso ao mesmo tempo, é algo que desafia "[...] uma tendência generalizada de polarizar o debate pela insistência de optar por isso ou aquilo". O paradoxo aqui exposto é representado por uma trajetória profissional marcada pela mesma essencialidade feminina que negou cidadania às mulheres. Em outras palavras, a identificação com uma essência de mulher, responsável pelo cuidado das pessoas, pela organização e limpeza do lar, possibilitou que as entrevistadas buscassem visibilidade e reconhecimento no mercado de trabalho. Para Butler (2010), discursos normativos de gênero não apenas regulam, mas também (re) produzem o que é ser homem ou mulher em uma determinada cultura. Para a autora, o gênero pode ser descrito como uma perfomance, o que significa dizer que os sujeitos "atuam" em conformidade com normas sociais que lhes conferem inteligibilidade social. Com base no que descreve Butler (2010), é possível relacionar as trajetórias marcadas por atividades historicamente consideradas femininas com normas de gênero, que são naturalizadas, tornando-as difíceis de serem percebidas e estranhadas. Cabe ressaltar que as normas de gênero são produzidas e reproduzidas por sujeitos em diferentes instituições sociais (por exemplo, família, escola, trabalho).

\section{Habilidades profissionais baseadas em uma "essencialidade feminina"}

Estudos feministas tem evidenciado persistentes desigualdades entre homens e mulheres no mercado de trabalho, destacando que as mulheres ainda recebem salários inferiores em relação aos homens e têm dificuldades em acessar cargos de maior prestígio (CAPPELLIN, 2008). A crença de que o cuidado com a casa, o marido e os filhos é responsabilidade das mulheres fomenta concepções de uma força de trabalho secundária e desqualificada e, portanto, desvalorizada em relação aos homens (ABRAMO, 2007). Sem razões concretas que justifiquem a desvalorização das mulheres em relação aos homens no mercado de trabalho, estudos sugerem que concepções baseadas em uma "essência feminina", que faz das mulheres sujeitos "naturalmente" hábeis para as atividades domésticas sustentam e (re) produzem desigualdades de gênero. Para Saffioti (2013), embora essas concepções tenham longa história e sejam percebidas nas mais diversas formas de organização social e econômica, o sistema capitalista soube aproveitar-se da posição social desvalorizada das mulheres em relação aos homens e explorá-la como forma de ampliação de mais-valor por meio de intensificação do trabalho, do aumento da jornada de trabalho e salários baixos. Por outro lado, habilidades baseadas em 
uma "essência feminina" podem ser utilizadas como forma de legitimar a participação das mulheres em espaços tradicionalmente masculinos.

Ao destacarem quais são as habilidades necessárias aos cargos de chefia que desempenham, um fator merece atenção especial. As entrevistadas relacionam habilidades profissionais e "essência feminina maternal" (o que diz de certa capacidade inata para "cuidar de"), em detrimento de habilidades adquiridas em formações específicas ou treinamentos.

Nem é faculdade que precisa, precisa ter paciência, por isso acho que uma mulher é melhor (Helena).

Sou bem mãezona com os funcionários (Neide).

Por cuidar da casa, sou bem jeitosa. Precisa ter jeito neste trabalho (Aparecida).

Tenho que saber lidar com as pessoas [...] entender e se colocar no lugar do outro (Luciana).

Tem que ter coração para entender os funcionários [...] na hora de demitir alguém, eu penso muito na família (Lúcia).

Tem que ser caprichosa para fazer o que eu faço (Nara).

Eu ser organizada, responsável e paciente é uma coisa que ajuda bastante no trabalho (Gorete).

As falas das entrevistadas evidenciam relações entre habilidades profissionais, corpo feminino e características ligadas à reprodução da vida. Segundo Beauvoir (1968), estudos acerca da mulher tendem a defini-la por suas características fisiológicas, mais detidamente, por seu aparelho reprodutor, como se a maternidade fosse o "destino" da mulher. O binário homem $\backslash$ mulher é o estandarte das normas reguladoras das relações de gênero. São estas normas que definem o que é ser um homem e uma mulher nas sociedades. Se durante o feminismo de primeira onda, as mulheres conquistaram direitos políticos que lhes eram negados, as normas que regulam as relações entre homens e mulheres são mais difíceis de serem transformadas.

Las normas pueden ser explícitas; sin embargo, cuando funcionan como el principio normalizador de la practica social a menudo permanecen implícitas; son difíciles de leer; los efectos que producen son la forma más clara y dramática mediante la cual se pueden discernir (BUTLER, 2012, p. 69). ${ }^{6}$

Ao relacionarem habilidades profissionais à determinada ideia de essência feminina, as entrevistadas não apenas naturalizam estas habilidades, mas também reificam as normas reguladoras de gênero que, entre outras questões, associam à mulher a maternidade. Para Butler (2012, p. 69), "que el género sea una norma sugiere que está siempre tenuemente incorporado en cualquier actor social". 7 As normas de gênero só existem em práticas sociais. Os sujeitos reificam as normas por meio de performances que visam à inteligibilidade de seus corpos. Se o

\footnotetext{
${ }^{6}$ As normas podem ser explícitas; no entanto, quando funcionam como o princípio regulador da prática social frequentemente permanecem implícitas; são difíceis de se ler; os efeitos que produzem são a forma mais dramática sobre a qual se pode discernir. (Tradução livre).

Que o gênero seja uma norma sugere que está sempre delicadamente incorporado em qualquer ator social. (Tradução livre).
}

binário homem\mulher é o que sustenta estas normas, é necessário eleger uma das posições para tornar os corpos inteligíveis. Os sujeitos performatizam por meio de gostos, comportamentos, atividades, desejos e corpos, aquilo que a norma "sugere" como ideal, mesmo que, em certa medida, performatizar signifique reforçar desigualdades de gênero. Normas de gênero no mercado de trabalho são utilizadas como justificativa para a subordinação das mulheres em relação aos homens. Porém, apesar da inserção desigual da força de trabalho feminina, sua participação no mercado de trabalho é uma forma de luta e resistência à situação de subordinação. Nas palavras de Butler (2011, p. 19) "prefiero existir en la subordinación que no existir: ésta sería una de las formulaciones del dilema (donde también hay un riesgo de muerte"8.

Quanto a um agente político que governa a ação de corpos, Foucault (1979, p. 151) questiona "[...] como ele pode ser tão sutil em sua distribuição, em seus mecanismos, seus controles recíprocos, seus ajustamentos, se não há quem tenha pensado em conjunto". Ainda para o autor, é importante destacar que as normas que regulamos sujeitos também são responsáveis por sua produção. Nas palavras de Butler (2010, p. 19), “o poder jurídico 'produz' inevitavelmente o que alega meramente representar; consequentemente, a política tem de se preocupar com essa função dual do poder: jurídica e produtiva". Com a intenção de serem representados por uma norma, os sujeitos performatizam estas normas. De certo modo, pode-se sugerir que as entrevistadas desta pesquisa performatizam as normas que regulam as relações de gênero como estratégias que visam à inserção e permanência no mercado de trabalho.

Outro indicador, construído a partir das entrevistas, diz de diferenças "naturais" entre homens e mulheres. As mulheres apresentam suas habilidades profissionais por meio de comparações/diferenciações com as habilidades masculinas.

\section{A mulher planeja e organiza, o homem age no ato (Luciana).}

O homem briga diferente, ele chega e explode. A mulher pensa bem antes [...] argumenta (Neide).

As mulheres são mais fortes, os homens são mais frágeis e reclamam mais (Aparecida).

Acho que as mulheres são mais responsáveis que os homens [...] os homens se comprometem menos, não conseguem fazer o mesmo trabalho durante tanto tempo (Gorete).

Os homens são mais razão, as mulheres mais coração (Helena).

Os homens chefes se impõem mais [...] os empregados têm mais medo deles (Lúcia).

Os homens ficam bravos e irritados [...] nós argumentamos numa reunião (Gorete).

A construção de tais "diferenciações" pode ser pensada a partir da trajetória do feminismo. Joana Pedro (2005) descreve que as lutas feministas passaram por

${ }^{8}$ Prefiro existir na subordinação do que não existir: esta é uma das formulações do dilema (onde também existe um risco de morte (Tradução livre).

Fractal, Rev. Psicol., v. 27 - n. 3, p. 301-309, 2015 
transformações no decorrer dos anos. A "segunda onda" do feminismo foi caracterizada pelo reconhecimento da diferença entre homens e mulheres. Por este motivo, as feministas de segunda onda foram chamadas de diferencialistas, pois " $[\ldots]$ estariam considerando que seria o sexo - no caso genital - que portavam o que promoveria a diferença em relação aos homens, e que lhes dava a identidade para as lutas contra a subordinação" (PEDRO, 2005 , p. 81). É possível perceber, nas falas das entrevistadas, concepções que apontam para o feminismo de segunda onda.

Na busca por uma participação e valorização igualitária em relação aos homens no mercado de trabalho, as mulheres entrevistadas reafirmam certa diferença. A identificação das entrevistadas com determinada essência feminina, considerada por muitas feministas como um dos pilares que sustentam a subordinação das mulheres em relação aos homens, é utilizada como uma forma de diferenciação e qualificação em relação à força de trabalho masculina.

Scott (2005) afirma que a busca pelo reconhecimento da cidadania faz com que os indivíduos acabem por reproduzirem as mesmas normas que os excluem. Com a intenção de se tornarem visíveis na busca pela cidadania, indivíduos acabam por estabelecerem uma identidade de grupo. Para Scott (2005, p. 18), "as identidades de grupo são um aspecto inevitável da vida social e da vida política, e as duas são interconectadas porque diferenças de grupo se tornam visíveis, salientes e problemáticas em contextos políticos específicos". Portanto, os elementos de exclusão que unem os indivíduos a grupos, elementos estes rejeitados pela identidade de grupo, são reproduzidos como forma de visibilidade e inclusão. Assim, como afirma Scott (2005, p. 15) "“...] os termos de exclusão sobre os quais essa discriminação está amparada são ao mesmo tempo negados e reproduzidos nas demandas pela inclusão".

\section{"Essência feminina" como estratégia de poder}

A articulação entre uma essência feminina e relações de poder pode ser observada nas entrevistas. Scott (1995, p. 88) descreve que "[...] o gênero é um campo primário no interior do qual, ou por meio do qual, o poder é articulado". Novamente aqui, é possível perceber elementos utilizados estrategicamente como uma forma de poder, uma forma de tornar especiais habilidades femininas em relação às masculinas.

Com nosso jeitinho conseguimos tudo (Neide).

Os empregados gostam bem mais do meu jeito e fazem tudo que peço com jeitinho (Luciana).

Até tem homem aqui que é inteligente, mas eu vou com meu jeitinho e acabo conseguindo as coisas (Gorete).

Eu sei lidar melhor com as pessoas [...] sei a hora certa de pedir [...] isso os homens não entendem (Helena).

O ideal é deixar que eles pensem que não estou mandando [...] pensem que eu estou pedindo [...] dá certo (Luciana).

Fractal, Rev. Psicol., v. 27 - n. 3, p. 301-309, 2015
Saffioti (1992) destaca que compreender a situação de subordinação das mulheres exige a articulação de gênero e classe social, problematizando, dessa forma, a relação entre patriarcado e capitalismo. Segundo a autora, mesmo nas sociedades que antecederam as sociedades capitalistas, assim como nas que se diferem, as mulheres são desigualmente valorizadas em relação aos homens. Enquanto os homens são valorizados por possuírem características que lhes permite desenvolver atividades relacionadas à vida pública - trabalho, política - a mulher é valorizada por características fundamentais para a realização de atividades na vida privada - afazeres domésticos, maternidade. Seria necessário acrescentar que, vistas como "naturais" e relacionadas ao cuidado e reprodução da espécie, as características das mulheres são valorizadas de forma distinta em relação aos homens, pois historicamente se considera que as habilidades masculinas necessitariam de qualificação continua para dar conta das exigências complexas da vida pública. Nesse sentido, é que Saffioti (1992) destaca a importância de concepções que remetem ao patriarcado e sua articulação com o sistema capitalista, sendo que, o mesmo se utiliza de desigualdades de gênero para desvalorizar a força de trabalho feminina, aprofundando, cada vez mais, a desvalorização da mulher como ser social.

Problematizando a participação das mulheres no mercado de trabalho a partir do que descreve Butler (2011) acerca da importância da performatização das normas gênero para a inteligibilidade social, é possível sugerir que, performatizá-las, então, pode ser um modo de legitimar as atividades realizadas pelas entrevistadas, embora características ligadas a certa "essência feminina" sejam desvalorizadas em relação aos homens no mercado de trabalho. Por meio de performances marcadas por concepções essencialistas, utilizadas como estratégias de poder, as mulheres abrem e disputam espaços de trabalho. Os discursos em torno da igualdade suscitados nas falas das entrevistadas são permeados por questões que remetem a diferenças. Por sua vez, as diferenças baseadas em uma essência feminina são reproduzidas e se tornam uma importante ferramenta de visibilidade. Butler (2010) explica que tem sido muito difícil romper com uma concepção generalizada do que seja uma "mulher".

La norma rige la inteligibilidad, permite que ciertos tipos de prácticas y acciones sean reconocibles como tales imponiendo una red de legibilidad sobre lo social e definiendo los parámetros de lo que aparecerá y lo que no aparecerá dentro de la esfera de lo social (BUTLER, 2012, p. 69). ${ }^{9}$

Se ora as normas que regulam as relações de gênero excluem e geram desigualdades em contextos públicos ou privados, é por meio delas que certa inteligibilidade social é produzida. Em outras palavras, se a concepção de uma essência comum a todas as mulheres tem servido como justificativa à subordinação em relação aos homens, sem performatizá-las, talvez, não fosse possível produzir inteligibilidade no mercado de trabalho. Este

${ }^{9}$ A norma que rege a inteligibilidade permite que certos tipos de práticas e ações sejam reconhecidas como tais impondo uma rede de legibilidade sobre o social e definindo os parâmetros do que aparecerá e do que não aparecerá dentro da esfera do social (Tradução livre). 
paradoxo faz com que seja necessário negar e reproduzir certa essencialidade feminina, como exercício de poder, em determinados contextos.

Foucault (1979) afirma que a ideia de um lugar fixo de poder é enganosa. Para o autor, o que existe são jogos de poder, dispositivos de poder que são estratégicos e manipulam as relações de força, distribuindo-as, talvez de forma desigual, mas não fixa. Entre os dispositivos de poder "[...] discursivos ou não, existe um tipo de jogo, ou seja, mudanças de posições, modificações de funções, que também podem ser muito diferentes" (FOUCAULT, 1979, p. 244). Desta forma, a partir do que apresenta Foucault, pode-se pensar que, talvez, a utilização de certa "essência feminina" muda de função quando muda de contexto. Em outras palavras, quando relacionada especificamente aos cuidados das crianças e limpeza dos lares, tal essência feminina pode privar as mulheres de direitos sociais, mas quando mobilizada no contexto profissional, como observado nas entrevistas, pode ser utilizada como estratégia de poder.

\section{Algumas considerações finais}

Nas últimas décadas, o aumento da participação das mulheres no mercado de trabalho é um fato inquestionável. A possibilidade de atuação em espaços até então considerados com "lugares de homens" vem se tornando cada vez mais frequente. Se a absorção da força de trabalho feminina (ainda) se faz, em grande parte, pelo "chão de fábrica", algumas mulheres, como as entrevistadas desta pesquisa, alcançaram cargos de chefia e, participam efetivamente de decisões importantes nas empresas em que trabalham. É central destacar que persistem algumas desigualdades entre homens e mulheres no mercado de trabalho, dentre elas, as diferenciações salariais que, embora não apareçam nas categorias aqui analisadas, foram citadas pelas entrevistadas e são frequentemente confirmadas por outros estudos. Os movimentos feministas, que buscam a igualdade social das mulheres em relação aos homens, sugerem que concepções baseadas em uma essência feminina têm sido responsável pela desvalorização da mão de obra feminina. Mas, de acordo com as entrevistadas, é possível sugerir que tal essência feminina tem se mostrado uma importante estratégia de poder na luta pelo reconhecimento social. De certa forma, ao tentarem se inserir em espaços historicamente ocupados por homens, as mulheres acabam por reproduzir normas que regulam as relações de gênero. É como se estas mulheres reproduzissem aquilo que se espera que elas sejam. Nesse processo, as mulheres entrevistadas lançam mão de certa essencialidade feminina para diferenciar e qualificar sua força de trabalho.

O que se pretendeu nesta pesquisa, entretanto, não foi encerrar as discussões acerca das relações de gênero no contexto do trabalho. A intenção é completamente oposta. Tratar de relações entre gênero e trabalho é fundamental para eliminar desigualdades que, embora antigas, parecem esquecidas, ou pouco lembradas em estudos de gênero. Os questionamentos acerca de trabalho e gênero ainda são muitos. As mulheres participam ativamente do mercado de trabalho, mas, em que condições? As atividades domésticas são igualmente divididas entre homens e mulheres? O discurso médico de cuidados a saúde do trabalhador pode, de certa forma, reforçar o discurso de uma essência feminina no contexto do trabalho? Os direitos a maternidade e amamentação, que visam proteger as mulheres trabalhadoras, podem discriminá-las em relação aos homens?

Espera-se que este trabalho possibilite a construção de conhecimentos acerca das relações de gênero e, ainda, que por meio dele se vislumbre novas possibilidades de pesquisa, visando maior igualdade entre homens e mulheres nos diversos contextos sociais.

\section{Referências}

ABRAMO, L. A inserção da mulher no mercado de trabalho: uma força de trabalho secundária? 2007. Tese (Doutorado)Departamento de Sociologia da Faculdade de Filosofia, Letras e Ciências Humanas, Universidade de São Paulo, São Paulo, 2007.

BEAUVOIR, S. O segundo sexo. São Paulo: Difusão Européia do Livro, 1968.

BUTLER, J. Problemas de gênero: feminismo e subversão da identidade. 3. ed. Rio de Janeiro: Civilização Brasileira. 2010.

BUTLER, J. Mecanismos psíquicos del poder. 3. ed. Madrid: Cátedra, 2011.

BUTLER, J. Deshacer el género. Barcelona: Paidós Ibérica, 2012.

CAPPELLIN, P. As desigualdades impertinentes: telhado, paredes ou céu de chumbo? Rev. Gênero, Niterói, v. 9, n. 1, 2008. Disponível em: <http://www.revistagenero.uff.br/index. php/revistagenero/article/view/97/73>. Acesso em: 09 mar. 2014.

DELPHY, C. Patrarcat (Théories du). In: HIRATA, H. et al. (Org.). Dictionnaire du feminisme. Paris: PUF, 2000.

FRIEDAN, B. Mistica feminina. Petrópolis, RJ: Vozes, 1971.

FOUCAULT, M. Microfísica do poder. Rio de Janeiro: Graal, 1979.

FOUCAULT, M. O sujeito e o poder. In: DREYFUS, H.; RABINOW, P. Michel Foucault: uma trajetória filosófica. Para além do estruturalismo e da hermenêutica. Rio de Janeiro: Forense Universitária, 1995. p. 231-249.

GALVANE, F. A. S. Gênero e trabalho: os sentidos produzidos por mulheres que ocupam cargos de chefia em indústrias de uma cidade do sul de Santa Catarina. 2009. Trabalho de Conclusão de Curso (Graduação em Psicologia)-Centro Universitário Barriga Verde - UNIBAVE, Orleans, SC, 2009.

GONZALEZ REY, F. L. Pesquisa qualitativa em Psicologia: caminhos e desafios. São Paulo: Pioneira Thomson Learning, 2005.

LAGO, M. C. S. Conceituando gênero: curso de atuação política para mulheres. Florianópolis: ICESPE, 1999.

MELO, H. P. de. Invisibilidade do trabalho feminino: uma violência disfarçada - notas preliminares. In: TORNQUIST, C. $\mathrm{S}$ et al. (Org.). Leituras de resistência: corpo, violência e poder. Florianópolis: Mulheres, 2009. p. 165-184. 
PEDRO, J. M. Traduzindo o debate: uso da categoria gênero na pesquisa histórica. História, São Paulo, v. 24, n. 1, 2005. p. 77-98.

SAFFIOTI, H. A mulher na sociedade de classes: mito e realidade. São Paulo: Expressão Popular, 2013.

SAFFIOTI, H. Rearticulando gênero e classe social. In: COSTA, A. O.; BRUSCHINI, C. (Org.). Uma questão de gênero. Rio de Janeiro: Rosa dos Tempos, 1992. p. 183-211.

SCOTT, J. Gênero: uma categoria útil de análise histórica. Revista Educação e Realidade, Porto Alegre, v. 20, n. 2, p. 7199, 1995.

SCOTT, J. O enigma da igualdade. Revista de Estudos Feministas, Florianópolis, v. 13, n. 1, p. 11-30, jan./abr. 2005.

SOUZA-LOBO, E. A classe operária tem dois sexos: trabalho, dominação e resistência. São Paulo: Brasiliense, 1991.

SOUZA-LOBO, E. A classe operária tem dois sexos: trabalho, dominação e resistência. 2. ed. São Paulo: Fundação Perseu Abramo, 2011.

Recebido em: 5 de julho de 2012 Aceito em: 1 de outubro de 2015 